\title{
EFEKTIVITAS OPERASIONAL PINTU AIR SALURAN SEKUNDER DAERAH IRIGASI KEDUNG LIMUS
}

\section{THE OPERATIONAL EFFECTIVENESS OF SECONDARY SLUICE CHANNEL IN KEDUNG LIMUS IRRIGATION AREA}

\author{
Teguh Marhendi ${ }^{1}$, Okti Kusuma Ningsih ${ }^{2}$ \\ ${ }^{12}$ Program Studi S1 Teknik Sipil, Fakultas Teknik dan Sains \\ Universitas Muhammadiyah Purwokerto
}

\section{Informasi Artikel}

Dikirim,

Direvisi,

Diterima,

\section{Korespondensi Penulis:}

Teguh Marhendi Program Studi Teknik Sipil Universitas Muhammadiyah Purwokerto

JL. K.H. Ahmad Dahlan Purwokerto, 53182

Email:

tmarhendi@gmail.com, teguhmarhendi@ump.ac.id

\section{ABSTRAK}

Bendung Arca atau Bendung Kali Pelus merupakan bendung yang melintasi Desa Arcawinangun Kecamatan Purwokerto Timur. Bendung Arca mempunyai 2 buah pintu pengambilan, ke arah kanan dan kiri. Saluran Induk Kedung Limus Arca sisi kanan mempunyai panjang saluran $1852 \mathrm{~m}$, dengan lebar dasar saluran rata-rata mencapai 2,50 meter dan sebagian besar dinding saluran telah dilinning (pasangan batu kali). Debit yang masuk intake pada saluran induk kanan yaitu $0,7736 \mathrm{~m} 3 / \mathrm{dt}$ dengan kebutuhan air pada saluran induk sebesar 34,7 lt/dt. Operasional pintu air pada Bendung Arca dilaksanakan berdasarkan 2 kondisi Elevasi Muka Air yaitu pada saat musim kemarau dan musim penghujan. Penelitian ini bertujuan untuk mengetahui efektivitas pintu-pintu air pada beberapa saluran sekunder. Dari hasil analisis efektivitas irigasi pada beberapa saluran sekunder Daerah Irigasi Kedung Limus, nilai efektivitas tertinggi pada saluran sekunder terdapat pada bulan September periode I dengan nilai efektivitas sebesar $100 \%$, sedangkan nilai efektivitas terendah terjadi pada bulan juni periode I dengan nilai efektifitas sebesar 21.

Kata Kunci : Saluran Sekunder, Efektivitas, Daerah Irigasi Kedung Limus

\section{ABSTRACT}

Arca Weir or Kali Pelus Weir is a weir that crosses Arcawinangun Village, East Purwokerto District. The Arca Weir has 2 retrieval gates, to the right and left. The main channel of Kedung Limus Arca on the right side has a channel length of $1852 \mathrm{~m}$, with an average channel width of 2.50 meters and most of the channel walls have been lined (river stone pairs). The discharge that enters the intake on the right main channel is $0.7736 \mathrm{m3} / \mathrm{s}$ with water demand in the main channel of $34.7 \mathrm{l} / \mathrm{s}$. The sluice gate operation at the Arca Weir is carried out based on 2 conditions of water level elevation, namely during the dry season and the rainy season. This study aims to determine the effectiveness of the floodgates in several secondary channels. From the results of the analysis of the effectiveness of irrigation in several secondary canals in the Kedung Limus Irrigation Area, the highest effectiveness value on the secondary canals was in September period I with an effectiveness value of $100 \%$, while the lowest effectiveness value occurred in June period I with an effectiveness value of 21 .

Keyword : Secondary Channels, Effectiveness, Kedung Limus Irrigation Area 


\section{PENDAHULUAN}

Bendung Arca atau Bendung Kali Pelus merupakan bendung yang melintasi Desa Arcawinangun Kecamatan Purwokerto Timur. Bendung ini di didirikan pada 1939 oleh pemerintah Hindia Belanda dengan tujuan untuk memenuhi kebutuhan irigasi lima kecamatan yaitu Kecamatan Kembaran, Sokaraja, Kalibagor, Purwokerto dan Purwokerto Barat dengan luas areal mencapai 1215,13 ha. Dengan luasan demikian, bendung ini adalah kewewenangan Dinas Sumber Daya Air Provinsi Jawa Tengah karena mengairi daerah irigasi > 1000 ha. Dalam pengoperasian bendung terdapat 8 POB ( Petugas Operasi Bendung) yang bertugas mengatur dan merawat bendung beserta saluran primer \& saluran sekunder. Panjang masing - masing saluran mencapai $13 \mathrm{~km}$ untuk saluran primer dan $7 \mathrm{~km}$ untuk saluran sekunder [1].

Bendung Arca adalah salah satu tipe bendung tetap, dengan karakteristik dari bendung berupa tidak adanya kolam lumpur. Alasan mengapa tidak terdapat kolam lumpur dikarenakan bangunan bendung ini dibangun di Sungai Pelus yang merupakan salah satu sungai jernih dari sekian sungai jernih yang ada di Kota Purwokerto. Dibawah mercu terdapat kolam olak dimana berfungsi untuk memecah turbulensi (air yang deras) [1].

Bendung Arca mempunyai karakteristik bangunan yang terdiri dari :

a) Mercu bendung

Mercu bendung memiliki panjang melintang sungai 39,30 $\mathrm{m}$ dan terdiri dari tiga undakan dibawah mercu. Dibuat berundaktersebut karena tinggi mercu bendung terhadap hilir sungai sangatlah curam, sehingga untuk mengurangi energi gravitasi dari air yang jatuh ke hilir, mercu tidak dibuat miring melainkan berundak.

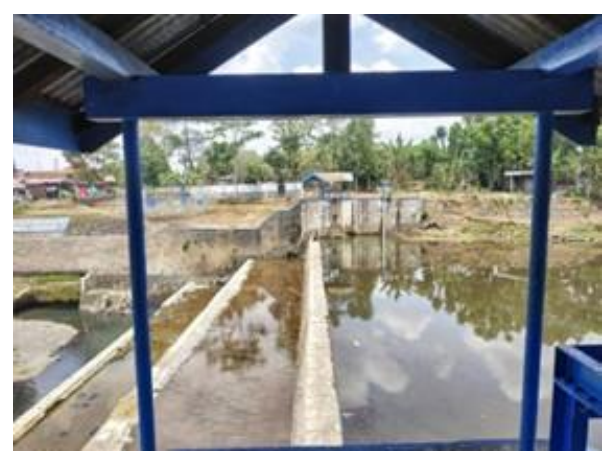

Gambar 1. Mercu Bendung Arca

b) Pintu pengambilan/ intake, terdiri dari pintu pengambilan kanan dan pintu pengambilan kiri.

c) Pintu Penguras/ Pembuang, terdiri dari pintu penguras kanan dan pintu penguras kiri.

d) Kolam olak, bendung ini mempunyai kolam olak yang terletak diarah horizontal masing - masing undak dan dibawah undak [1].

Operasi Bendung Arca dilaksanakan berdasarkan 2 (dua) kondisi Elevasi Muka Air yaitu:

a) Musim penghujan rata-rata yang terjadi pada bulan Januari sampai dengan bulan Agustus rata-rata muka air dan debit di Bendung Arca lebih tinggi. Pada kondisi ini pintu utama terbuka, sehingga air banjir bisa mengalir.

b) Musim kemarau yang terjadi pada bulan September sampai dengan bulan Desember rata-rata muka air dan debit di Bendung Arca lebih rendah, sehingga muka air perlu dinaikkan sesuai yang harus dipertahankan dengan jalan melakukan pengoperasian (penutupan) pintu utama [1] [2] [3] [4] [5] [6] [7.

Daerah Irigasi Kedunglimus Arca berada di bawah pengelolaan Perwakilan Balai Wilayah Tajum, Balai PSDA Serayu Citanduy Dinas PSDA Propinsi Jawa Tengah. Jaringan Irigasi Kedunglimus Arca merupakan jaringan irigasi teknis dengan sistim irigasi ganda yang meliputi pengambilan dariBendung Arca, sedangkan lahan sawah irigasi areal Arca Kanan 380,48 Ha merupakan daerah dataran, sedangkan saluran pembawanya merupakan saluran galian [1] [2] [3].

Bendung Arca mempunyai 2 (dua) buah pengambilan ke arah kanan dan kiri, untuk pengambilan kearah kanan Saluran Induk Kedunglimus Arca mempunyai panjang saluran $1852 \mathrm{~m}$, dengan lebar dasar rata-rata 2,50 meter dan sebagian besar telah dilinning (pasangan batu kali), sedangkan debit yang masuk intake pada saluran induk yaitu $0.7736 \mathrm{~m} 3 / \mathrm{dt}$ dengan kebutuhan air pada saluran induk sebesar 34,7 1t/dt. Pada saluran induk Kedunglimus Arca kanan terdapat tiga saluran sekunder yaitu saluran Sekunder Balekambang, Sakuran Sekunder Kali Akum, Saluran Sekunder Pliken [1].

Efektivitas irigasi merupakan faktor penentu utama dari unjuk kerja suatu sistem jaringan irigasi. Efektvitas irigasi terdiri atas efektivitas pengaliran yang pada umumnya terjadi di jaringan utama dan efektivitas CIVeng Vol.1, No.1, Januari 2020 : 23 38 
di jaringan sekunder yaitu dari bangunan pembagi sampai petak sawah (Direktorat Jendral Pengairan,1986). Pada daerah irigasi masalah distribusi air irigasi sering terjadi yaitu apabila besaran debit yang tersedia lebih kecil dari kebutuhan air dilapangan (terutama pada saat musim kemarau), sehingga penggunaan air irigasi secara efisien sangat diperlukan. Hasil produksi irigasi (panen) dipengaruhi bukan saja oleh banyaknya tingkat pemenuhan kebutuhan air, tetapi juga diantaranya oleh cara pemberian air [2] [3] [4] [5] [6] [7] [8] [9] [10] [11] [12] [13] [14].

Kebutuhan akan ketersediaan air perlu diperhatikan karena air merupakan salah satu kebutuhan pokok dalam sektor pertanian. Kekurangan air yang terjadi dapat menyebabkan terjadinya alih fungsi lahan. (Ginanjar Pangestu, 2015). Berdasarkan Informasi dari Perwakilan Balai Pekerjaan Umum Taru Serayu Citanduy bahwa Ketersediaan Air di Daerah Irigasi Kedung Limus belum cukup untuk memenuhi kebutuhan air yang diperlukan pada lahan sawah, untuk itu di perlukan pengaturan pengoperasian pintu air. Hal ini disebabkan oleh beberapa faktor seperti terjadinya sedimentasi pada aliran irigasi, rusaknya jaringan irigasi, dan sebagian air diambil untuk kebutuhan perikanan bukan untuk kebutuhan di sawah [2] [3] [4] [5] [6] [7] [8] [13] [15].

Arsyid, 2009, melakukan analisis tentang Pengaturan Pintu Irigasi Mrican Kanan Dalam Pengoperasian Kebutuhan Air Irigasi. Berdasarkan penelitian tersebut diketahui bahwa pembagian air di daerah irigasi Mrican Kanan dengan areal seluas 15.764 ha tidak terdistribusi merata. Studi tentang pintu air telah dilakukan di daerah ini untuk memecahkan masalah. Daerah penelitian adalah daerah irigasi Papar dengan panjang saluran antara pintu regulator adalah 7496 meter [6].

Ronaldo, 2006, melakukan analisis tentang Bukaan Pintu Air dan Efisiensi Aliran pada Daerah Irigasi. Hasilnya adalah Sumber daya air sangat diperlukan untuk aspek hidup dan kehidupan, baik manusia, makhluk hidup lainnya maupun lingkungan. Peningkatan kebutuhan akibat pertambahan penduduk dan peningkatan kesejahteraan masyarakat memacu pemanfaatan sumber daya alam, termasuk sumber daya air. Penelitian ini dilakukan dengan maksud hasil yang diperoleh dari penelitian dapat meningkatkan pemahaman terhadap pengaruh elevasi di hulu pintu untuk keperluan operasi jaringan. Dari hasil penelitian diperoleh bukaan pintu sorong yang bervariasi akan menimbulkan elevasi muka air yang bervariasi baik di hulu maupun di hilir. Kecepatan aliran yang dihasilkan juga bervariasi namun debit yang di hasilkan sama besarnya. Pengoperasian bukaan pintu sorong pada saluran irigasi bertujuan untuk mengukur pembagian air dengan teliti ke saluran saluran yang dilayani. Pintu sorong juga berfungsi untuk mengatur debit dan tinggi muka air sesuai dengan kebutuhan yang diperlukan [5].

Vika, dkk, 2014, melakukan analisis tentang Evaluasi Kinerja Jaringan Irigasi di Saluran Sekunder pada Berbagai Tingkat Pemberian Air Di Pintu Ukur. Berdasarkan hasil penelitiannya diperoleh bahwa Daerah irigasi Way Rarem merupakan salah daerah irigasi yang difokuskan untuk meningkatkan produktifitas tanaman pangan di provinsi Lampung. Luas areal layanan baku Daerah Irigasi Way Rarem diperkirakan sebesar 22.960 hektar. Akan tetapi, dalam kenyataannya luas layanan baku untuk daerah irigasi ini masih belum tercapai. Berdasarkan permasalahan yang dikemukakan di atas maka perlu adanya suatu kajian untuk mengetahui permasalahan yang terjadi salah satunya adalah dengan melihat pengaruh bukaan pintu terhadap kinerja jaringan irigasi [14].

\section{METODE PENELITIAN}

\subsection{Lokasi Penelitian}

Bendung Arca terletak dalam Wilayah Kerja Administrasi Desa Dukuhwaluh, Kecamatan Kembaran, Kabupaten Banyumas, sedangkan lokasi Daerah Irigasi Kedung Limus Arca berada dibawah pengelolaan Perwakilan Balai Wilayah Tajum. Balai PSDA Serayu Citanduy, Dinas PSDA Provinsi Jawa Tengah.

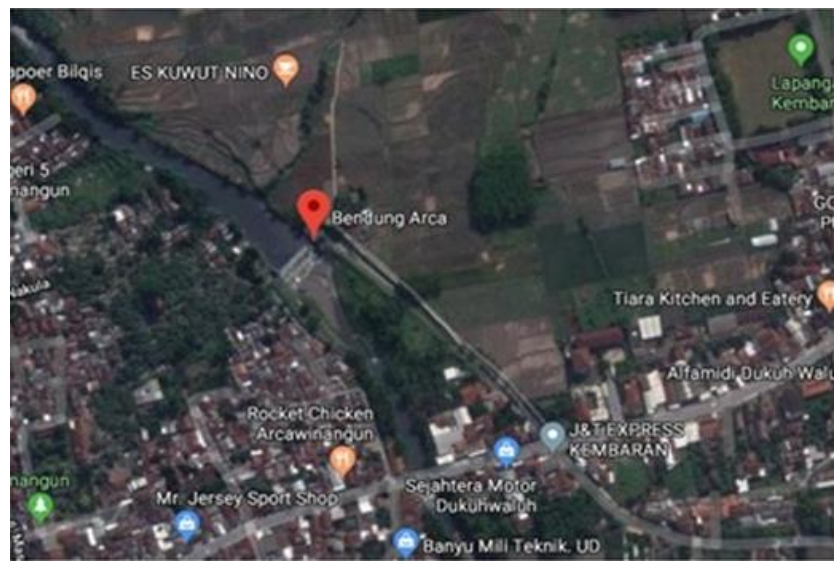

Gambar 2. Lokasi Bendung Arca [1] 


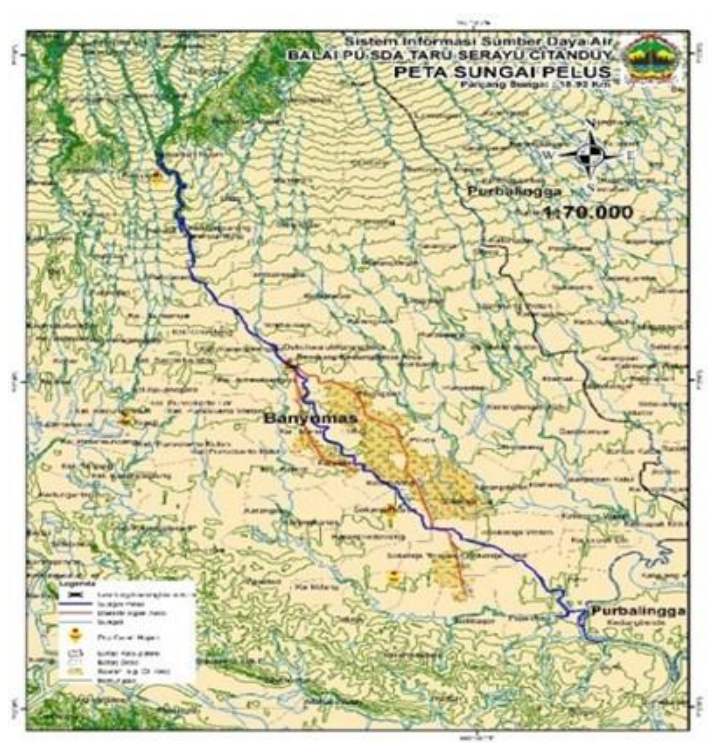

Gambar 3.Peta Sungai Pelus [1]

\subsection{Data penelitian}

Data yang diperlukan dalam penelitian ini terdiri atas data primer berupa survei lapangan pada jaringan irigasi induk dan sekunder serta data sekunder yang diperoleh dari pihak Dinas terkait seperti Dinas Pengairan Pertambangan dan Energi (Disairtamben) Kabupaten Banyumas, Dinas Pertanian, dan Balai PSDA Serayu Citanduy Dinas PSDA Jawa Tengah.

Data-data yang diperlukan dalam penelitian ini adalah:

a) Peta Daerah Irigasi Sungai Pelus.

b) Data hujan selama 10 tahun terakhir.

c) Data debit sungai di Bendung Arca selama 10 tahun terakhir.

d) Data debit bukaan pintu air saluran sekunder

e) Pola tanam daerah irigasi kedung limus

f) Jenis tanaman daerah irigasi kedung limus

\subsection{Analisis Kebutuhan Air Irigasi}

Kebutuhan air irigasi dianalisis berdasarkan kebutuhan air tanaman (di lahan) dan kebutuhan air pada bangunan pengambilan (di bendung). Analisis kebutuhan air untuk tanaman di lahan dipengaruhi oleh beberapa faktor berikut,

a) pengolahan lahan,

b) penggunaan konsumtif,

c) perkolasi,

d) penggantian lapis air, dan

e) sumbangan hujan efektif.

Sedangkan kebutuhan air di pintu pengambilan atau bangunan utama dipengaruhi oleh luas areal tanam, kebutuhan air untuk tanaman di lahan dan efisiensi, sebagaimana diperlihatkan dalam persamaan berikut ini [7][10] [11] [12] [13] [14].

$$
\mathrm{DR}=\frac{\mathrm{IR} \cdot(\mathrm{A})}{\mathrm{Ef}}
$$

$$
\begin{array}{cl}
\text { dengan, } & \\
\text { DR } & : \text { kebutuhan air di pintu pengambilan (1/dt) } \\
\text { IR } & : \text { Kebutuhan air irigasi (1/dt/ha) } \\
\text { A } & : \text { Luas areal irigasi (ha) } \\
\text { Ef } & \text { : efisiensi jaringan irigasi total (\%), (59\%-73\%). }
\end{array}
$$

Mengacu pada Direktorat Jenderal Pengairan (1986) maka efisiensi irigasi secara keseluruhan diambil $90 \%$ dan tingkat tersier $80 \%$. Angka efisiensi irigasi keseluruhan tersebut dihitung dengan cara mengkonversi efisiensi di masing-masing tingkat yaitu $0,9 \times 0,9 \times 0,8=0,648 \approx 65 \%$ [7]. 


\subsection{Imbangan Air}

Untuk mengetahui bagaimana kebutuhan air irigasi dapat dilayani oleh ketersediaan air yang ada. Sehingga diketahui apakah mengalami kelebihan air (surplus) ataukah kekurangan air (defisit) [7].

\subsection{Analisis Efektivitas Jaringan Irigasi}

Tingkat efektifitas saluran irigasi adalah tingkat kemampuan saluran mengalirkan air untuk melayani kebutuhan air pada petak-petak pelayanan. Tingkat efektifitas saluran dipengaruhi oleh perubahan dimensi saluran dan luasan areal pelayanan setelah perencanaan [7][10] [11] [12] [13] [14].

\section{HASIL DAN PEMBAHASAN}

\subsection{Analisis Kebutuhan Air irigasi}

Evapotranspirasi (Eto)

Evapotranspirasi dihitung dengan rumus Blaney Criddle, Langkah perhitungan evapotranspirasi adalah sebagai berikut :

Tabel 1. Nilai P untuk metode Blaney Criddle

\begin{tabular}{|c|c|c|c|c|c|c|c|c|c|c|c|c|}
\hline $\begin{array}{l}\text { Lintang } \\
\text { Utara } \\
\text { selatan } \\
\end{array}$ & $\begin{array}{l}\text { Jan } \\
\text { Jul }\end{array}$ & $\begin{array}{l}\text { Feb } \\
\text { Ags }\end{array}$ & $\begin{array}{l}\text { Mar } \\
\text { Sep }\end{array}$ & $\begin{array}{l}\text { Apr } \\
\text { Okt }\end{array}$ & $\begin{array}{l}\text { Mei } \\
\text { Nov }\end{array}$ & $\begin{array}{l}\text { Jun } \\
\text { Des }\end{array}$ & $\begin{array}{l}\text { Jul } \\
\text { Jan }\end{array}$ & $\begin{array}{l}\text { Ags } \\
\text { Feb }\end{array}$ & $\begin{array}{l}\text { Sep } \\
\text { Mar }\end{array}$ & $\begin{array}{l}\text { Okt } \\
\text { Apr }\end{array}$ & $\begin{array}{l}\text { Nov } \\
\text { Mei }\end{array}$ & $\begin{array}{l}\text { Des } \\
\text { Jun }\end{array}$ \\
\hline 60 & 0,15 & 0,2 & 0,26 & 0,32 & 0,38 & 0,41 & 0,4 & 0,34 & 0,28 & 0,22 & 0,17 & 0,13 \\
\hline 50 & 0,19 & 0,23 & 0,27 & 0,31 & 0,34 & 0,36 & 0,35 & 0,32 & 0,28 & 0,24 & 0,2 & 0,18 \\
\hline 40 & 0,22 & 0,24 & 0,27 & 0,3 & 0,32 & 0,34 & 0,33 & 0,31 & 0,28 & 0,25 & 0,22 & 0,21 \\
\hline 30 & 0,24 & 0,25 & 0,27 & 0,29 & 0,31 & 0,32 & 0,31 & 0,3 & 0,28 & 0,26 & 0,24 & 0,23 \\
\hline 20 & 0,25 & 0,26 & 0,27 & 0,28 & 0,29 & 0,3 & 0,3 & 0,29 & 0,28 & 0,26 & 0,25 & 0,25 \\
\hline 10 & 0,26 & 0,27 & 0,27 & 0,28 & 0,28 & 0,29 & 0,29 & 0,28 & 0,28 & 0,27 & 0,26 & 0,26 \\
\hline 0 & 0,27 & 0,27 & 0,27 & 0,27 & 0,27 & 0,27 & 0,27 & 0,27 & 0,27 & 0,27 & 0,27 & 0,27 \\
\hline
\end{tabular}

Mencari data suhu rata - rata bulanan (t). Berdasarkan data klimatologi (PSDA Citanduy Purwokerto).

Tabel 2. Hasil Perhitungan Evapotranspirasi

\begin{tabular}{cllll}
\hline No & Bulan & $\mathrm{t}$ & $\mathrm{P}$ & $\mathrm{ET}_{\mathrm{O}}$ \\
\hline 1 & Januari & 25,1 & 0,29 & 5,68 \\
2 & Februari & 25,3 & 0,28 & 5,51 \\
3 & Maret & 25,1 & 0,28 & 5,49 \\
4 & April & 25,1 & 0,27 & 5,29 \\
5 & Mei & 25,2 & 0,26 & 5,11 \\
6 & Juni & 23,7 & 0,26 & 4,93 \\
7 & Juli & 24,6 & 0,26 & 5,04 \\
8 & Agustus & 25,4 & 0,27 & 5,33 \\
9 & September & 25,4 & 0,27 & 5,33 \\
10 & Oktober & 25,8 & 0,28 & 5,58 \\
12 & November & 26 & 0,28 & 5,60 \\
12 & Desember & 25,4 & 0,29 & 5,72 \\
\hline (Sumber : Analisis Perhitungan Evapotranspirasi, 2020)
\end{tabular}

Contoh Perhitungan :

$$
\begin{aligned}
& \text { Eto }=\mathrm{P}(0,457 \times \mathrm{t}+8,13) \\
& \text { Eto }=0,29(0,457 \times 25,1+8,13) \\
& 5.68 \mathrm{~mm}
\end{aligned}
$$

Keterangan :

1. Mencari nilai (P) dari tabel 4.1 Blaney Criddle berdasarkan letak lintang $7^{\circ}$ LS. Letak Lintang $7^{\circ}$ $\mathrm{LS}, \mathrm{P}=0,29$

2. Mencari data suhu rata - rata bulanan (T)

Berdasarkan data klimatologi (PSDA Serayu Citaduy) pada tebel 4.1 di dapat nilai $\mathrm{T}=25,1$ 


\section{Penyiapan Lahan (Ir)}

Untuk menghitung kebutuhan air yang dibutuhkan untuk penyiapan lahan (Ir) yang dilakukan adalah :

- $\quad$ Menghitung nilai Eo $+\mathrm{P}$

Contoh menghitung nilai Eo $+\mathrm{P}$, pada bulan januari sebagai berikut :

$\mathrm{Eo}+\mathrm{P}=(1,1 \times \mathrm{ETo})+2$

$$
=8,25 \mathrm{~mm}
$$

Nilai P diambil pada tabel 4.1 pada bulan Januari. Karena tekstur tanah di daerah irigasi Kedunglimus adalah sedang (lempung kepasiran), sehingga angka perkolasi diambil $2 \mathrm{~mm} / \mathrm{hari}$. Untuk bulan februari dan selanjutnya dihitung dengan cara yang sama, seperti tersaji pada Tabel 4.3

\begin{tabular}{|c|c|c|c|}
\hline No & Bulan & ETo & $\mathrm{Eo}+\mathrm{P}$ \\
\hline 1 & Januari & 5.68 & 8.25 \\
\hline 2 & Februari & 5.51 & 8.07 \\
\hline 3 & Maret & 5.49 & 8.04 \\
\hline 4 & April & 5.29 & 7.82 \\
\hline 5 & Mei & 5.11 & 7.62 \\
\hline 6 & Juni & 4.93 & 7.42 \\
\hline 7 & Juli & 5.04 & 7.54 \\
\hline 8 & Agustus & 5.33 & 7.86 \\
\hline 9 & September & 5.33 & 7.86 \\
\hline 10 & Oktober & 5.58 & 8.14 \\
\hline 11 & November & 5.60 & 8.16 \\
\hline 12 & Desember & 5.72 & 8.30 \\
\hline
\end{tabular}

Selanjutnya nilai Eo + P yang diperoleh, digunakan untuk mendapatkan kebutuhan air selama penyiapan lahan. Lihat pada Tabel 4.4 kebutuhan air selama penyiapan lahan. Waktu yang dibutuhkan air selama penyiapan lahan (T) untuk tanaman padi diambil selama 30 hari dan nilai (S) sebesar $300 \mathrm{~mm}$. Jika nilai Eo+P berada diantara nilai pada Tabel 4.4, maka dilakukan interpolasi sebagai berikut :

Contoh nilai Eo + P pada bulan Januari $=8,25$ ( berada diantara 8 dan 8,5), Maka kebutuhan air untuk penyiapan lahan dihitung :

$$
\begin{aligned}
& =\frac{[(8,5-8,25) \cdot 14,8]+[(8,25-8,0) \cdot 14,5]}{(8,5-8)} \\
& =14,65 \mathrm{~mm} / \text { hari. }
\end{aligned}
$$

Tabel 4. Rekapitulasi Kebutuhan Air untuk penyimpanan Lahan

\begin{tabular}{lll}
\hline Bulan & $\mathbf{I r}(\mathbf{m m} / \mathbf{h r})$ & $\mathbf{I r}(\mathbf{l t} / \mathbf{d t})$ \\
\hline Oktober & 14,58 & 1,69 \\
November & 14,60 & 1,69 \\
Desember & 14,68 & 1,70 \\
Januari & 14,65 & 1,70 \\
Februari & 13,04 & 1,51 \\
Maret & 13,02 & 1,51 \\
April & 12,86 & 1,49 \\
Mei & 12,70 & 1,47 \\
Juni & 14,15 & 1,64 \\
Juli & 14,22 & 1,65 \\
Agustus & 14,42 & 1,67 \\
September & 14,42 & 1,67 \\
(Sumber : Analisis Perhitungan Ir,2020)
\end{tabular}

Keterangan :

$1 \mathrm{~mm} / \mathrm{hari}=1 / 8,64 \mathrm{l} / \mathrm{dt} / \mathrm{ha}$ 


\section{Penggunaan Konsumtif}

Penggunaan komsumtif diartikan sebagai jumlah air yang dibutuhkan untuk pertumbuhan tanaman. (Doorenbos dkk., 1977) mendefinisikan kebutuhan air tanaman sebagai jumlah air yang disediakan untuk mengimbangi air yang hilang akibat evaporasi dan transpirasi (evapotranspirasi). Penggunaan komsumtif air di dapat dari evapotranspirasi dikalikan dengan angka koefisien tanaman . Padi yang ditanam di areal sawah Daerah Irigasi Kedunglimus berjenis IR64 yang termasuk padi FAO varietas biasa. Tanaman palawija di Daerah Irigasi Kedung Limus diasumsikan tanaman jagung karena sebagian besar petani menanam jagung.

Angka kebutuhan air konsumtif bulan oktober sebagai berikut :

$$
\begin{aligned}
\text { Etc } & =\text { ETo } \times \mathrm{Kc} \\
\text { Etc } & =5,58 \times 1,10 \\
& =6,14 \mathrm{~mm} / \text { hari }
\end{aligned}
$$

\begin{tabular}{|c|c|c|c|c|c|}
\hline MT & Bulan & & ETo (mm) & kc & Etc (mm/hari) \\
\hline \multirow{8}{*}{ MT I } & Okt & $\mathrm{I}$ & 5.58 & 1.10 & 6.14 \\
\hline & & II & 5.58 & 1.10 & 6.14 \\
\hline & Nov & $\mathrm{I}$ & 5.60 & 1.10 & 6.16 \\
\hline & & II & 5.60 & 1.10 & 6.16 \\
\hline & Des & I & 5.72 & 1.10 & 6.29 \\
\hline & & II & 5.72 & 1.05 & 6.01 \\
\hline & Jan & I & 5.68 & 0.95 & 5.40 \\
\hline & & II & 5.68 & 0.00 & 0.00 \\
\hline \multirow{8}{*}{ MT II } & Feb & $\mathrm{I}$ & 5.51 & 1.10 & 6.06 \\
\hline & & II & 5.51 & 1.10 & 6.06 \\
\hline & Mar & I & 5.49 & 1.10 & 6.04 \\
\hline & & II & 5.49 & 1.10 & 6.04 \\
\hline & Apr & $\mathrm{I}$ & 5.29 & 1.10 & 5.82 \\
\hline & & II & 5.29 & 1.05 & 5.55 \\
\hline & Mei & $\mathrm{I}$ & 5.11 & 0.95 & 4.85 \\
\hline & & II & 5.11 & 0.00 & 0.00 \\
\hline \multirow{8}{*}{ MT III } & Jun & I & 4.93 & 0.00 & 0.00 \\
\hline & & II & 4.93 & 0.00 & 0.00 \\
\hline & Jul & I & 5.04 & 0.50 & 2.52 \\
\hline & & II & 5.04 & 0.59 & 2.97 \\
\hline & Ags & I & 5.33 & 0.96 & 5.12 \\
\hline & & II & 5.33 & 1.05 & 5.60 \\
\hline & Sep & I & 5.33 & 1.02 & 5.44 \\
\hline & & II & 5.33 & 0.95 & 5.06 \\
\hline
\end{tabular}

Tabel 5. Angka Konsumtif Air (Etc)

\section{Perkolasi (P)}

Berdasarkan teksturnya angka perkolasi berbeda beda, yaitu :

- $\quad$ Berat (lempung) $=1-2 \mathrm{~mm} / \mathrm{hari}$

- Sedang (lempung kepasiran) $=2-3 \mathrm{~mm} / \mathrm{hari}$

- $\quad$ Ringan $=3-6 \mathrm{~mm} / \mathrm{hari}$

Menurut studi lapangan dan juga mengacu pada penelitian sebelumnya dan terdahulu tekstur tanah di daerah irigasi Kedunglimus adalah sedang (lempung kepasiran), sehingga angka perkolasi diambil 2 $\mathrm{mm} / \mathrm{hari}$.

\section{Penggantian Lapisan Air (Wlr)}

Penggantian lapisan air dilakukan sebanyak $2 \mathrm{kali}$, masing - masing $50 \mathrm{~mm}(3,33 \mathrm{~mm} / \mathrm{hari})$ selama sebulan dan dua bulan setelah transplantasi atau pemindahan bibit ( Direktorat Jendral Pengairan, 1986).Dalam hal ini, penggantian lapisan air dilakukan pada bulan November dan Januari untuk masa tanam pertama dan bulan Maret dan Mei untuk masa tanam kedua. 


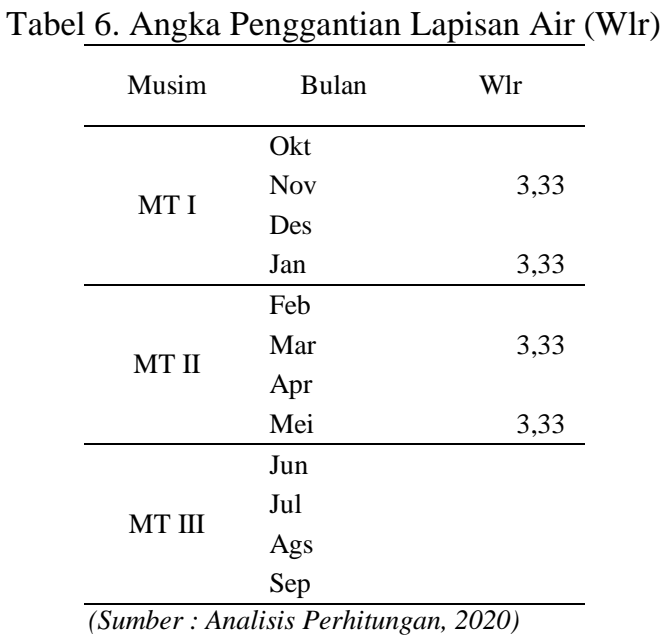

\section{Curah Hujan Rata - Rata}

Cara Perhitungan curah hujan rata - rata 30 hari di DAS Sungai Pelus dengan menggunakan Metode Poligon Thiessen. Adapun jumlah stasiun yang masuk di lokasi DAS Sungai Pelus berjumlah tiga buah stasiun yaitu Sta. Rempoah, Sta. Arca dan Sta. Sokaraja. Penentuan luas pengaruh stasiun hujan dengan Metode Thiessen, dari tiga stasiun tersebut masing - masing dihubungkan untuk memperoleh luas daerah pengaruh dari tiap stasiun. Di mana masing - masing stasiun mempunyai daerah pengaruh yang dibentuk dengan garis - garis sumbu tegak lurus terhadap garis penghubung antara stasiun, dapat dilihat pada gambar 4.4 :

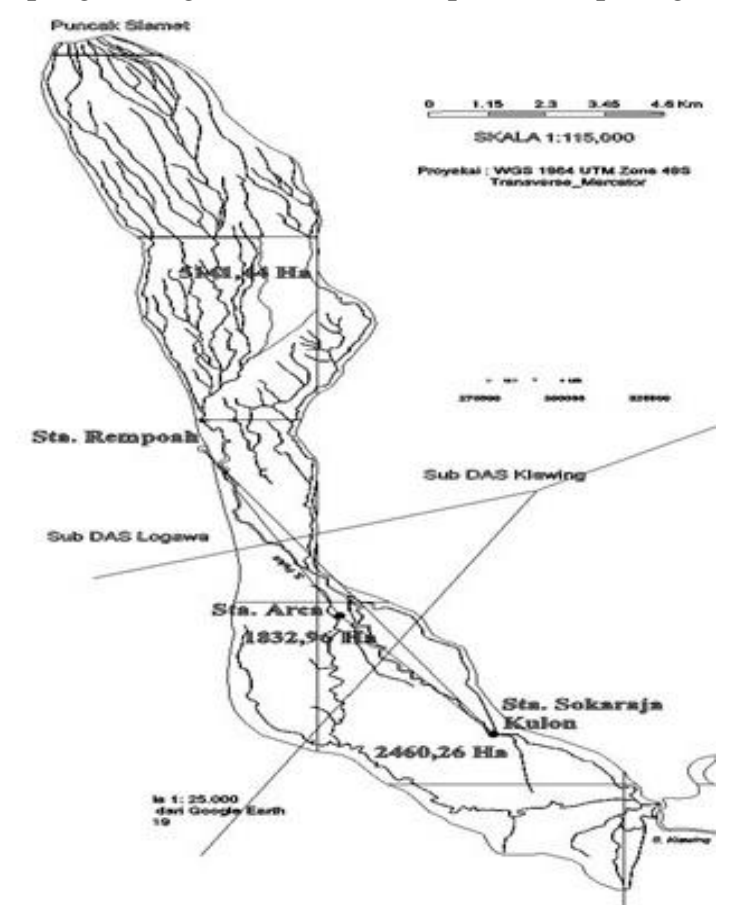

Gambar 4. Luas DAS Pelus dengan Metode Poligon Thiessen

(Sumber : Hasil Analisis 2020)

Data hujan yang digunakan dalam analisis ini meliputi data curah hujan selama 10 tahun pada Stasiun Rempoah, Stasiun Arca dan Stasiun Sokaraja. Data curah hujan dan luasan DAS Sungai Pelus berdasarkan Metode Poligon Thiessen dihitung untuk mencari Rerata Curah Hujan per tahun. Perhitungan curah hujan rerata tiap Stasiun Curah hujan didapat dari jumlah curah hujan dan jumlah hari hujan pertahun dengan perhitungan seperti dibawah ini.

Curah Hujan Rerata Perhari $(\mathrm{mm})=\frac{\text { Jumlah Curah Hujan }(\mathrm{mm})}{\text { Jumlah Hari Hujan Pertahun }}$

Contoh perhitungan curah hujan harian St. Rempoah tahun 2010 : 


$$
\begin{array}{r}
\text { Curah Hujan Rerata Perhari }(\mathrm{mm})=\frac{\text { Jumlah Curah Hujan }(\mathrm{mm})}{\text { Jumlah Hari Hujan Pertahun }} \\
=\frac{7111}{289} \\
=24,606 \mathrm{~mm}
\end{array}
$$

Selanjutnya dengan cara yang sama seperti tersaji pada Tabel 7, Tabel 8 dan Tabel 9.

Tabel 7. Perhitungan Curah Hujan Rata Rata (Sta. Rempoah)

\begin{tabular}{|c|c|c|c|c|}
\hline Tahun & $\begin{array}{l}\text { Jumlah Curah } \\
\text { Hujan (mm) }\end{array}$ & $\begin{array}{l}\text { Jumlah Hari } \\
\text { Hujan Pertahun }\end{array}$ & $\begin{array}{l}\text { Rerata Curah } \\
\text { Hujan Harian } \\
(\mathrm{mm})\end{array}$ & $\begin{array}{l}\text { Luas Daerah } \\
\text { Stasiun }\end{array}$ \\
\hline 2010 & 5006 & 199 & 25,153 & 18,33 \\
\hline 2011 & 3483 & 151 & 23,063 & 18,33 \\
\hline 2012 & 3012 & 110 & 27,385 & 18,33 \\
\hline 2013 & 3488 & 140 & 24,914 & 18,33 \\
\hline 2014 & 3197 & 129 & 24,783 & 18,33 \\
\hline 2015 & 2977 & 105 & 28,352 & 18,33 \\
\hline 2016 & 4270 & 179 & 23,855 & 18,33 \\
\hline 2017 & 4642 & 165 & 28,133 & 18,33 \\
\hline 2018 & 2625 & 105 & 25,000 & 18,33 \\
\hline 2019 & 2016 & 95 & 21,221 & 18,33 \\
\hline
\end{tabular}

\begin{tabular}{lllll}
\hline Tahun & $\begin{array}{l}\text { Jumlah Curah } \\
\text { Hujan }(\mathrm{mm})\end{array}$ & $\begin{array}{l}\text { Jumlah } \\
\text { Hujan } \\
\text { Pertahun }\end{array}$ & $\begin{array}{l}\text { Hari } \\
\begin{array}{l}\text { Rerata Curah } \\
\text { (mm) }\end{array}\end{array}$ & $\begin{array}{l}\text { Luas Daerah } \\
\text { Stasiun }\end{array}$ \\
\hline 2010 & 7111 & 289 & 24,606 & 51,41 \\
2011 & 3967 & 184 & 21,560 & 51,41 \\
2012 & 3807 & 160 & 23,796 & 51,41 \\
2013 & 4104 & 218 & 18,826 & 51,41 \\
2014 & 3531 & 198 & 17,833 & 51,41 \\
2015 & 3639 & 161 & 22,602 & 51,41 \\
2016 & 5700 & 243 & 23,457 & 51,41 \\
2017 & 5104 & 191 & 26,723 & 51,41 \\
2018 & 4154 & 158 & 26,291 & 51,41 \\
2019 & 2967 & 143 & 20,748 & 51,41 \\
\hline (Sumber: Analisis Perhitungan, 2020$)$ & \multicolumn{3}{l}{}
\end{tabular}

Tabel 8. Perhitungan Curah Hujan Rata Rata (Sta. Arca)

Tabel 9. Perhitungan Curah Hujan Rata Rata (Sta. Sokaraja Kulon)

\begin{tabular}{clllll}
\hline Tahun & $\begin{array}{l}\text { Jumlah Curah } \\
\text { Hujan }(\mathrm{mm})\end{array}$ & $\begin{array}{l}\text { Jumlah } \\
\text { Hujan Pertahun }\end{array}$ & $\begin{array}{c}\text { Hari } \\
\text { Hujan } \\
(\mathrm{mm})\end{array}$ & $\begin{array}{l}\text { Rerata } \\
\text { Harian }\end{array}$ & $\begin{array}{l}\text { Luas Daerah } \\
\text { Stasiun }\end{array}$ \\
\hline 2010 & 5006 & 199 & 25,153 & 24,60 \\
2011 & 3483 & 151 & 23,063 & 24,60 \\
2012 & 3012 & 110 & 27,385 & 24,60 \\
2013 & 3488 & 140 & 24,914 & 24,60 \\
2014 & 3197 & 129 & 24,783 & 24,60 \\
2015 & 2977 & 105 & 28,352 & 24,60 \\
2016 & 4270 & 179 & 23,855 & 24,60 \\
2017 & 4642 & 165 & 28,133 & 24,60 \\
2018 & 2625 & 105 & 25,000 & 24,60 \\
2019 & 2016 & 95 & 21,221 & 24,60 \\
\hline (Sumber : Analisis Perhitungan, 2020$)$ & &
\end{tabular}

Setelah dihitung curah hujan rerata harian ( $\mathrm{mm}$ ) setiap stasiun curah hujan Rempoah, Arca, dan Sokaraja Kulon selama 10 tahun terakhir, Selanjutnya menghitung Rerata Curah Hujan (mm) / Pertahun Selama 10 tahun terakhir dengan perhitungan sebagai berikut : 
dimana :

$$
\bar{R}=\frac{A_{1} R_{1}+A_{2} R_{2}+A_{3} R_{3}}{A_{1}+A_{2}+A_{3}}
$$

$\overline{\mathrm{R}}=$ Curah hujan rata-rata Pertahun ( $\mathrm{mm} /$ Pertahun)

A1 = Luas pengaruh dari stasiun pengamatan St. Rempoah (ha)

A2 = Luas pengaruh dari stasiun pengamatan St. Arca (ha)

A3 = Luas pengaruh dari stasiun pengamatan St. Sokaraja Kulon (ha)

$\overline{\mathrm{R}} 1=$ Curah hujan rata-rata Pertahun St. Rempoah $(\mathrm{mm})$

$\overline{\mathrm{R}} 2=$ Curah hujan rata-rata Pertahun St. Arca (mm)

$\overline{\mathrm{R}} 3=$ Curah hujan rata-rata Pertahun St. Sokaraja Kulon (mm)

Tabel 10. Perhitungan Curah Hujan dengan Metode Poligon Thiessen

\begin{tabular}{cccccc}
\hline No & Tahun & $\begin{array}{c}\text { Curah Hujan } \\
\text { Sta. Rempoah } \\
(\mathrm{mm})\end{array}$ & $\begin{array}{c}\text { Curah Hujan } \\
\text { Sta. Arca } \\
(\mathrm{mm})\end{array}$ & $\begin{array}{c}\text { Curah Hujan } \\
\text { Sta. Sokaraja } \\
\text { Kulon }(\mathrm{mm})\end{array}$ & $\begin{array}{c}\text { Curah Hujan } \\
\text { Rerata }(\mathrm{mm})\end{array}$ \\
\hline 1 & 2010 & 24.606 & 25,153 & 25.156 & 24,85 \\
2 & 2011 & 21.560 & 23,063 & 23.066 & 22,24 \\
3 & 2012 & 23.794 & 27,385 & 27.382 & 25,43 \\
4 & 2013 & 18.826 & 24,914 & 24.914 & 21,60 \\
5 & 2014 & 17.833 & 24,783 & 24.783 & 21,00 \\
6 & 2015 & 22.602 & 28,352 & 28.352 & 25,22 \\
7 & 2016 & 23.457 & 23,855 & 23.855 & 23,64 \\
8 & 2017 & 26.723 & 28,133 & 28.133 & 27,36 \\
9 & 2018 & 26.291 & 25,000 & 25.000 & 25,70 \\
10 & 2019 & 20.748 & 21,221 & 21.221 & 20,96 \\
\hline \multicolumn{7}{l}{ Sumber: Analisis Perhitungan 2020} & &
\end{tabular}

Keterangan :

$\begin{array}{ll}\text { Luas Sta. Rempoah } & =226.44 \mathrm{~mm} \\ \text { Luas Sta. Arca } & =251.85 \mathrm{~mm} \\ \text { Luas Sta Sokaraja Kulon } & =251.86 \mathrm{~mm}\end{array}$

\section{Curah Hujan Efektif (Re)}

Menurut (Ginanjar Pangestu, 2015) Curah hujan efektif adalah curah hujan yang secara efektif dan secara langsung dipergunakan memenuhi kebutuhan air tanaman untuk pertumbuhan. Besarnya curah hujan efektif untuk tanaman ditentukan sebesar $80 \%$ dari curah hujan rerata per 15 harian bulanan dengan kemungkinan kegagalan $20 \%$ atau dapat juga disebut dengan curah hujan $R_{80}$ untuk perhitungan curah hujan efektif ini menggunakan metode Basic Year dengan rumus : $R_{80}=\mathrm{n} / 5+1$ dengan $\mathrm{n}$ adalah periode lama pengamatan.

Tabel 11. Curah Hujan Efektif (Re)

\begin{tabular}{|c|c|c|c|c|}
\hline \multirow{2}{*}{ Masa Tanam } & \multirow{2}{*}{ Bulan } & \multirow{2}{*}{ Periode } & \multicolumn{2}{|c|}{ Curah Hujan Efektif } \\
\hline & & & Re Padi & Re Palawija \\
\hline \multirow{8}{*}{ MT I } & Oktober & I & 0,01 & 0,01 \\
\hline & & II & 0,21 & 0,15 \\
\hline & November & I & 0,66 & 0,47 \\
\hline & & II & 0,53 & 0,38 \\
\hline & Desember & I & 0,54 & 0,39 \\
\hline & & II & 0,84 & 0,60 \\
\hline & Januari & I & 0,95 & 0,68 \\
\hline & & II & 0,89 & 0,63 \\
\hline \multirow{8}{*}{ MT II } & Februari & I & 0,79 & 0,57 \\
\hline & & II & 0,78 & 0,56 \\
\hline & Maret & I & 0,52 & 0,37 \\
\hline & & II & 0,70 & 0,50 \\
\hline & April & I & 0,68 & 0,48 \\
\hline & & II & 0,52 & 0,37 \\
\hline & Mei & I & 0,14 & 0,10 \\
\hline & & II & 0,23 & 0,16 \\
\hline
\end{tabular}

CIVeng Vol.1, No.1, Januari $2020: 23 \sim 38$ 


\begin{tabular}{llcll} 
& Juni & I & 0,16 & 0,11 \\
& & II & 0,08 & 0,06 \\
\multirow{3}{*}{ MT III } & Juli & I & 0,00 & 0,00 \\
& & II & 0,00 & 0,00 \\
& \multirow{2}{*}{ Agustus } & I & 0,00 & 0,00 \\
& & II & 0,00 & 0,00 \\
& September & I & 0,00 & 0,00 \\
& & II & 0,00 & 0,00 \\
\hline \multicolumn{2}{l}{ Sumber : (Analisis Perhitungan,2020) } & &
\end{tabular}

\subsection{Kebutuhan Air Irigasi}

Faktor yang mempengaruhi kebutuhan air irigasi yaitu Evapotranspirasi (ETo), Penyiapan Lahan (Ir), Penggunaan Komsumtif Air (Etc), Perkolasi (P), Penggantian Lapisan Air (Wlr), Curah Hujan Efektif (Re), maka kebutuhan air irigasi adalah sebagai berikut :

Tabel 12. Tabel Kebutuhan Air Irigasi

\begin{tabular}{|c|c|c|c|c|c|c|c|c|c|c|}
\hline \multirow{2}{*}{ Musim } & \multirow{2}{*}{ Bulan } & \multirow{2}{*}{ Periode } & \multirow{2}{*}{$\begin{array}{l}\text { Etc } \\
\mathrm{mm} / \mathrm{hri}\end{array}$} & \multirow{2}{*}{$I r$} & \multirow{2}{*}{$\begin{array}{l}W l \boldsymbol{r} \\
K P-01\end{array}$} & \multirow{2}{*}{$P$} & \multirow{2}{*}{$\boldsymbol{R e}$} & \multirow{2}{*}{$\begin{array}{l}\text { NFR } \\
\text { mm/hari }\end{array}$} & \multirow{2}{*}{$\begin{array}{l}\text { NFR } \\
l / d t / h a\end{array}$} & \multirow{2}{*}{$\begin{array}{l}\text { keb.di } \\
\text { intake }\end{array}$} \\
\hline & & & & & & & & & & \\
\hline \multirow{8}{*}{ MT I } & \multirow{2}{*}{ Okt } & I & 6.14 & \multirow{2}{*}{1.69} & \multirow{6}{*}{3.33} & \multirow{2}{*}{2} & 0.01 & 9.82 & 1.14 & 1.75 \\
\hline & & II & 6.14 & & & & 0.21 & 9.62 & 1.11 & 1.71 \\
\hline & \multirow{2}{*}{ Nov } & I & 6.16 & \multirow{6}{*}{1.69} & & \multirow{2}{*}{2} & 0.66 & 12.52 & 1.45 & 2.23 \\
\hline & & II & 6.16 & & & & 0.53 & 12.65 & 1.46 & 2.25 \\
\hline & \multirow{2}{*}{ Des } & I & 6.29 & & & \multirow{2}{*}{2} & 0.54 & 7.75 & 0.90 & 1.38 \\
\hline & & II & 6.01 & & & & 0.84 & 7.17 & 0.83 & 1.28 \\
\hline & \multirow{2}{*}{ Jan } & I & 5.40 & & \multirow{2}{*}{3.33} & \multirow{2}{*}{2} & 0.95 & 9.78 & 1.13 & 1.74 \\
\hline & & II & 0.00 & & & & 0.89 & 4.44 & 0.51 & 0.79 \\
\hline \multirow{8}{*}{ MT II } & \multirow{2}{*}{$\mathrm{Feb}$} & I & 6.06 & \multirow{2}{*}{1.51} & \multirow{4}{*}{3.33} & \multirow{2}{*}{2} & 0.79 & 8.78 & 1.02 & 1.56 \\
\hline & & II & 6.06 & & & & 0.78 & 8.79 & 1.02 & 1.57 \\
\hline & \multirow{2}{*}{ Mar } & I & 6.04 & \multirow{2}{*}{1.51} & & 2 & 0.52 & 12.36 & 1.43 & 2.20 \\
\hline & & II & 6.04 & & & 2 & 0.7 & 12.18 & 1.41 & 2.17 \\
\hline & & I & 5.82 & & & & 0.68 & 7.14 & 0.83 & 1.27 \\
\hline & Apr & II & 5.55 & & & 2 & 0.52 & 7.03 & 0.81 & 1.25 \\
\hline & Mei & I & 4.85 & & 333 & 2 & 0.14 & 10.04 & 1.16 & 1.79 \\
\hline & Niel & II & 0.00 & & 3.53 & 2 & 0.23 & 5.10 & 0.59 & 0.91 \\
\hline & Jup & I & 0.00 & & & 2 & 0.11 & 1.89 & 0.22 & 0.34 \\
\hline & Jun & II & 0.00 & & & 2 & 0.06 & 1.94 & 0.22 & 0.35 \\
\hline & & I & 2.52 & & & & 0 & 7.85 & 0.91 & 1.40 \\
\hline & Jul & II & 2.97 & & 3.33 & 2 & 0 & 8.30 & 0.96 & 1.48 \\
\hline M1 III & & I & 5.12 & & & & 0 & 7.12 & 0.82 & 1.27 \\
\hline & Ags & II & 5.60 & & & 2 & 0 & 7.60 & 0.88 & 1.35 \\
\hline & Sen & I & 5.44 & & 333 & 2 & 0 & 10.77 & 1.25 & 1.92 \\
\hline & sep & II & 5.06 & & 3.53 & 2 & 0 & 10.39 & 1.20 & 1.85 \\
\hline
\end{tabular}

Contoh Perhitungan Kebutuhan Air Irigasi pada Tabel 12 pada Bulan Oktober dapat dilihat seperti dibawah ini.

1. Menghitung NFR

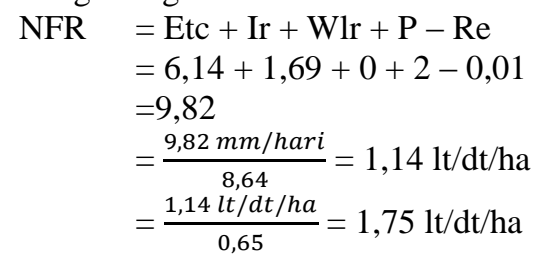

2. Perhitungan kebutuhan air di intake, adalah sebagai berikut :

$$
=\frac{1,14 l t / d t / h a}{0,65}=1,75 \mathrm{lt} / \mathrm{dt} / \mathrm{ha}
$$


Untuk menghitung kebutuhan Air Irigasi Sekunder Balekambang diperoleh dg mengalikan kebutuhan air irigasi di intake dg luas areal sawah saluran sekunder Balekambang, seperti tersaji pada Tabel 4.13

Tabel 13. Kebutuhan Air Irigasi di Saluran Sekunder Balekambang

\begin{tabular}{|c|c|c|c|c|c|}
\hline \multirow[t]{2}{*}{ MT } & \multirow{2}{*}{ Bulan } & \multirow{2}{*}{ Periode } & \multirow{2}{*}{$\begin{array}{l}\text { Keb. di intake } \\
\text { lt/dt/ha }\end{array}$} & \multirow{2}{*}{$\begin{array}{l}\text { Luas areal SS } \\
\text { Balekambang } \\
\text { ha }\end{array}$} & \multirow{2}{*}{$\begin{array}{l}\text { Keb. Air } \\
\text { irigasi } \\
\text { lt/dt }\end{array}$} \\
\hline & & & & & \\
\hline \multirow{8}{*}{ MT I } & \multirow[t]{2}{*}{ Oktober } & I & 1.75 & 142,25 & 248.73 \\
\hline & & II & 1.71 & 142,25 & 243.67 \\
\hline & \multirow[t]{2}{*}{ November } & I & 2.23 & 142,25 & 317.12 \\
\hline & & II & 2.25 & 142,25 & 320.42 \\
\hline & \multirow[t]{2}{*}{ Desember } & I & 1.38 & 142,25 & 196.30 \\
\hline & & II & 1.28 & 142,25 & 181.61 \\
\hline & \multirow[t]{2}{*}{ Januari } & I & 1.74 & 142,25 & 247.72 \\
\hline & & II & 0.79 & 142,25 & 112.46 \\
\hline \multirow{8}{*}{ MT II } & \multirow[t]{2}{*}{ Februari } & I & 1.56 & 142,25 & 222.39 \\
\hline & & II & 1.57 & 142,25 & 222.65 \\
\hline & \multirow[t]{2}{*}{ Maret } & I & 2.20 & 142,25 & 313.07 \\
\hline & & II & 2.17 & 142,25 & 308.51 \\
\hline & \multirow[t]{2}{*}{ April } & I & 1.27 & 142,25 & 180.85 \\
\hline & & II & 1.25 & 142,25 & 178.07 \\
\hline & \multirow[t]{2}{*}{ Mei } & I & 1.79 & 142,25 & 254.31 \\
\hline & & II & 0.91 & 142,25 & 129.18 \\
\hline \multirow{8}{*}{ MT III } & \multirow[t]{2}{*}{ Juni } & I & 0.34 & 142,25 & 47.87 \\
\hline & & II & 0.35 & 142,25 & 49.14 \\
\hline & \multirow[t]{2}{*}{ Juli } & I & 1.40 & 142,25 & 198.84 \\
\hline & & II & 1.48 & 142,25 & 210.23 \\
\hline & \multirow[t]{2}{*}{ Agustus } & I & 1.27 & 142,25 & 180.35 \\
\hline & & II & 1.35 & 142,25 & 192.50 \\
\hline & \multirow[t]{2}{*}{ September } & I & 1.92 & 142,25 & 272.80 \\
\hline & & II & 1.85 & 142,25 & 263.17 \\
\hline
\end{tabular}

\subsection{Analisis Efektivitas Irigasi}

Tingkat efektivitas saluran irigasi adalah tingkat kemampuan saluran mengalirkan air untuk melayani kebutuhan air pada petak-petak pelayanan. Tingkat efektivitas saluran dipengaruhi oleh perubahan dimensi saluran dan luasan areal pelayanan setelah perencanaan. Untuk mengukur tingkat efektivitas jaringan irigasi terutama pada jaringan irigasi primer dan sekunder menurut (Suroso, 2006) dapat menggunakan persamaan sebagai berikut :

$$
\mathrm{EF}_{\mathrm{i}}=\left(\mathrm{Q}_{\mathrm{renc}, \mathrm{i}} / \mathrm{Q}_{\mathrm{eks}, \mathrm{i}}\right) \times 100 \%
$$

Dengan :

$$
\begin{aligned}
& \mathrm{EF}_{\mathrm{i}} \quad \text { : Tingkat efektivitas jaringan irigasi pada saluran } \mathrm{i} ; \\
& \mathrm{Q}_{\text {renc,i }} \quad \text { : Debit rencana pemberian air } \\
& \mathrm{Q}_{\mathrm{eks}, \mathrm{i}} \quad \text { : Debit eksisting saluran } \mathrm{i} \\
& \mathrm{i}: \text { Saluran primer dan saluran sekunder yang ada didaerah irigasi Kedunglimus Arca. }
\end{aligned}
$$

Kriteria efektivitas indeks kinerja jaringan irigasi, menurut Peraturan Menteri Pekerjaan Umum No. 32/ 32/PRT/M/2007, adalah sebagai berikut :
- $\quad 80 \%-100 \%$
- $\quad 70 \%-79 \%$
: Kinerja sangat baik
- $\quad 55 \%-69 \%$
Kinerja Baik
$-\quad<55 \%$
: Kinerja kurang dan perlu perhatian
$->100 \%$
: Kinerja jelek dan perlu perhatian
: Kinerja kurang baik/rendah
- Maksimum 100\% , minimal 55\% dan optimum 77,5\% 
Tabel 14. Debit Saluran Sekunder Balai Kambang D.I. Kedung Limus Tahun 2020

\begin{tabular}{|c|c|}
\hline $\begin{array}{l}\text { Muka } \\
\text { Air }\end{array}$ & Debit \\
\hline$(\mathrm{cm})$ & $\left(\mathrm{m}^{3} / \mathrm{dt}\right)$ \\
\hline 0 & 0.000 \\
\hline 1 & 0.012 \\
\hline 2 & 0.025 \\
\hline 3 & 0.037 \\
\hline 4 & 0.049 \\
\hline 5 & 0.061 \\
\hline 6 & 0.074 \\
\hline 7 & 0.086 \\
\hline 8 & 0.098 \\
\hline 9 & 0.111 \\
\hline 10 & 0.123 \\
\hline 11 & 0.135 \\
\hline 12 & 0.148 \\
\hline 13 & 0.160 \\
\hline 14 & 0.172 \\
\hline 15 & 0.184 \\
\hline 16 & 0.197 \\
\hline 17 & 0.209 \\
\hline 18 & 0.218 \\
\hline 19 & 0.228 \\
\hline 20 & 0.237 \\
\hline 21 & 0.246 \\
\hline 22 & 0.255 \\
\hline 23 & 0.265 \\
\hline 24 & 0.274 \\
\hline 25 & 0.283 \\
\hline 26 & 0.292 \\
\hline 27 & 0.302 \\
\hline 28 & 0.311 \\
\hline 29 & 0.320 \\
\hline 30 & 0.329 \\
\hline 31 & 0.339 \\
\hline 32 & 0.348 \\
\hline 33 & 0.357 \\
\hline 34 & 0.366 \\
\hline 35 & 0.376 \\
\hline 36 & 0.385 \\
\hline 37 & 0.394 \\
\hline 38 & 0.403 \\
\hline 39 & 0.413 \\
\hline 40 & 0.422 \\
\hline 41 & 0.431 \\
\hline 42 & 0.440 \\
\hline 43 & 0.450 \\
\hline 44 & 0.459 \\
\hline 45 & 0.468 \\
\hline 46 & 0.477 \\
\hline 47 & 0.487 \\
\hline 48 & 0.496 \\
\hline 49 & 0.505 \\
\hline 50 & 0.514 \\
\hline
\end{tabular}


Tabel 15. Debit Saluran Sekunder untuk masa awal tanam

\begin{tabular}{|c|c|c|c|c|}
\hline MT & Bulan & Periode & Muka Air & Debit Sekunder \\
\hline \multirow{8}{*}{ MT I } & \multirow{2}{*}{ Okt } & I & 35 & 376 \\
\hline & & II & 33 & 357 \\
\hline & \multirow{2}{*}{ Nov } & I & 32 & 348 \\
\hline & & II & 30 & 329 \\
\hline & \multirow{2}{*}{ Des } & I & 25 & 283 \\
\hline & & II & 20 & 237 \\
\hline & \multirow{2}{*}{ Jan } & I & 22 & 255 \\
\hline & & II & 17 & 209 \\
\hline \multirow{8}{*}{ MT II } & \multirow{2}{*}{ Feb } & I & 30 & 329 \\
\hline & & II & 29 & 320 \\
\hline & \multirow{2}{*}{ Mar } & I & 30 & 329 \\
\hline & & II & 29 & 320 \\
\hline & \multirow{2}{*}{ Apr } & I & 16 & 197 \\
\hline & & II & 15 & 184 \\
\hline & \multirow{2}{*}{ Mei } & I & 22 & 255 \\
\hline & & II & 11 & 135 \\
\hline \multirow{8}{*}{ MT III } & \multirow{2}{*}{ Jun } & I & 19 & 228 \\
\hline & & II & 18 & 218 \\
\hline & \multirow{2}{*}{ Jul } & I & 17 & 209 \\
\hline & & II & 18 & 218 \\
\hline & \multirow{2}{*}{ Agst } & I & 18 & 218 \\
\hline & & II & 16 & 197 \\
\hline & \multirow{2}{*}{ Sep } & I & 24 & 274 \\
\hline & & II & 24 & 274 \\
\hline
\end{tabular}

(Sumber : Analisis Perhitungan, 2020)

Mengacu Tabel 15 di atas, maka dapat ditentukan efektivitas Saluran Sekunder seperti dibawah ini.

Tabel 16. Analisis Efektivitas Saluran Sekunder

\begin{tabular}{|c|c|c|c|c|}
\hline Bulan & Periode & $\begin{array}{l}\text { Debit SS } \\
\text { Balekambang (lt/dt) }\end{array}$ & $\begin{array}{l}\text { Kebutuhan air irigasi } \\
\text { (lt/dt) }\end{array}$ & $\begin{array}{l}\text { Efektivitas } \\
(\%)\end{array}$ \\
\hline \multirow[t]{2}{*}{ Oktober } & I & 376 & 248.73 & $66 \%$ \\
\hline & II & 357 & 243.67 & $68 \%$ \\
\hline \multirow[t]{2}{*}{ November } & I & 348 & 317.12 & $91 \%$ \\
\hline & II & 329 & 320.42 & $97 \%$ \\
\hline \multirow[t]{2}{*}{ Desember } & I & 283 & 196.30 & $69 \%$ \\
\hline & II & 237 & 181.61 & $77 \%$ \\
\hline \multirow[t]{2}{*}{ Januari } & I & 255 & 247.72 & $97 \%$ \\
\hline & II & 209 & 112.46 & $54 \%$ \\
\hline \multirow[t]{2}{*}{ Februari } & I & 329 & 222.39 & $68 \%$ \\
\hline & II & 320 & 222.65 & $70 \%$ \\
\hline \multirow[t]{2}{*}{ Maret } & I & 329 & 313.07 & $95 \%$ \\
\hline & II & 320 & 308.51 & $96 \%$ \\
\hline \multirow[t]{2}{*}{ April } & I & 197 & 180.85 & $92 \%$ \\
\hline & II & 197 & 178.07 & $97 \%$ \\
\hline \multirow[t]{2}{*}{ Mei } & I & 255 & 254.31 & $100 \%$ \\
\hline & II & 135 & 129.18 & $96 \%$ \\
\hline \multirow[t]{2}{*}{ Juni } & I & 228 & 47.87 & $21 \%$ \\
\hline & II & 218 & 49.14 & $23 \%$ \\
\hline \multirow[t]{2}{*}{ Juli } & I & 209 & 198.84 & $95 \%$ \\
\hline & II & 218 & 210.23 & $96 \%$ \\
\hline \multirow[t]{2}{*}{ Agustus } & I & 218 & 180.35 & $83 \%$ \\
\hline & II & 197 & 192.50 & $98 \%$ \\
\hline \multirow[t]{2}{*}{ September } & I & 274 & 272.80 & $100 \%$ \\
\hline & II & 274 & 263.17 & $96 \%$ \\
\hline
\end{tabular}


Pada Tabel 16 efektivitas pada Saluran Sekunder tertinggi terdapat pada bulan September periode I dengan nilai efektitivitas sebesar $100 \%$, Sehingga Derah Irigasi Kedung Limus pada bulan September periode I dapat dikatakan telah mencapai kinerja sangat baik karna telah mencapai angkat maksimum 100\% dari Kriteria efektivitas indeks kinerja jaringan irigasi, sedangkan efektivitas terendah terdapat pada bulan Juni periode I dengan nilai efektivitas sebesar $21 \%$, Sehingga Derah Irigasi Kedung Limus pada bulan Juni periode I termasuk Kinerja jelek dan butuh perhatian karna hasil yang diperoleh kurang dari angka minimal 55\% dari Kriteria efektivitas indeks kinerja jaringan irigasi dan nilai efektivitas rata-rata sebesar $80.99 \%$ Sehingga nilai rata-rata Derah Irigasi Kedung Limus dapat dikatakan kinerja sangat baik karna hasil yang diperoleh mendekati angkat maksimum $100 \%$ dari Kriteria efektivitas indeks kinerja jaringan irigasi.

\section{KESIMPULAN}

Dari hasil perhitungan analisa efektivitas irigasi pada saluran sekunder Daerah Irigasi Kedung Limus, dapat dismpulkan bahwa nilai efektivitas tertinggi pada saluran sekunder terdapat pada bulan September periode I dengan nilai efektivitas sebesar 100\%, sehingga Daerah Irigasi Kedung Limus pada bulan September periode I dapat dikatakan telah mencapai kinerja sangat baik. Sedangkan nilai efektivitas terendah terjadi pada bulan juni periode I dengan nilai efektifitas sebesar $21 \%$, sehingga Daerah Irigasi Kedung Limus pada bulan juni periode I dapat dikatakan Kinerja jelek.

\section{DAFTAR PUSTAKA}

[1] Perwakilan Balai Wilayah Tajum, 2016, Uraian Singkat Daerah Kedunglimus Arca, Balai Pengelolaan Sumber Daya Air Serayu Citanduy Purwokerto.

[2] Khan, M.H., \& Saleem, N., 2005, Influence of Different Irrigation Intervals on Growth and Yield of Bell Pepper, Research Journal of Agriculture and Biological Science, 1(2), 125-128.

[3] Pangestu, Ginanjar, 2015, Analisis Efisiensi Distribusi Air Irigasi Pada Saluran Primer dan Sekunder D.I Karangnangka. Jurnal Teknik Sipil : Universitas Muhammadiyah Purwokerto.

[4] Ramadhan, Fahrul., Tarigon. 2013. Evaluasi Kinerja Saluran Jaringan Irigasi Jeuram Kabupaten Nagan Raya. Jurnal Teknik Sipil : Universitas Sumatera Utara

[5] Ronaldo, 2006, Analisis Bukaan Pintu Air dan Efisiensi Aliran pada Daerah Irigasi. Jurnal Teknik Sipil : Universitas Jendral Soedirman

[6] Arsyid, 2009, Pengaturan Pintu Irigasi Dalam Pengoperasian Kebutuhan Air Irigasi, Jurnal Teknik Sipil : Universitas Tanjungpura.

[7] Direktorat Jendral Pengairan, Departemen Pekerjaan Umum, 1986, Standar Perencanaan Irigasi: Kriteria Perencanaan Jaringan Irigasi (KP-01), Jakarta.

[8] Doorenbons, j., and Pruitt, W., o., 1997, Guidelines For Predicting Crop WaterRequirements, Food And Agriculture Organitation Od The United Nation, Rome.

[9] Erdem, T., Erdem, Y., Orta, H., \& Okursoy, H., 2006, Water-Yield Relationships of Potato under Different Irrigation Methods and Regimens, Journal of Science and Agriculture, 63 (3), 226-231.

[10] Menteri Pekerjaan Umum, No.32/32/PRT/M/2007, Kriteria efektivitas indeks kinerja jaringan irigasi : Universitas Tanjungpura.

[11] Simbolon, benny., 2014. Kajian Jaringan Efektivitas Saluran Irigasi Di Daerah Irigasi Gerinis. Jurnal Mahasiswa Teknik Sipil : Universitas Tanjungpura.

[12] Suroso, 2006. Elevasi Kinerja Jaringan Irigasi Banjaran untuk Meningkatkan Efektivitas dan Efesiensi Pengelolaan Air Irigasi. Digital Collection UPT Perpustakaan UNSOED. Universitas Jendral Soedirman.

[13] Susanto, Akmar. 2004, Efektivitas Operasional Bendung Tirol Untuk Distribusi AirDaerah Irigasi Limbangan Madukara-Banjarnegara. Jurnal Mahasiswa Teknik Sipil : Universitas Muhammadiyah Purwokerto.

[14] Vika, dkk. 2014, Evaluasi Kinerja Jaringan Irigasi di Saluran Sekunder pada Berbagai Tingkat Pemberian Air Di Pintu Ukur. Jurnal Teknik Sipil : Universitas Tanjungpura.

[15] Kartasapoetra,. AG., Mul. Mulyani., dan F. Pollein. 1990, Teknologi Pengairan Pertanian (irigasi). Bumi Aksara. Jakarta. 
